\title{
One Pot Synthesis of Amino-Functionalized Magnetite/Silica Nanocomposites in Microemulsion
}

\author{
Zheng Zhang ${ }^{1, a}$, Wei Zhang ${ }^{2, b^{*}}$ \\ ${ }^{1}$ Department of Mechanical Engineering, Academy of Armored Forces Engineering, Beijing \\ 100072, China \\ ${ }^{2}$ School of marine science and technology, Hebei University of Technology, Tianjin 300130, China
}

Keywords: amino-functionalized; magnetic silica; microemulsion; immobilization

Abstract. Amino-functionalized magnetite/Silica $\left(\mathrm{Fe}_{3} \mathrm{O}_{4} / \mathrm{SiO}_{2}\right)$ nanoparticles were synthesized in water-in-oil microemulsion system by one-pot process. The structure composition and the surface functional groups of the product were characterized. The synthesized product was embedded structure of $\mathrm{Fe}_{3} \mathrm{O}_{4} / \mathrm{SiO}_{2}$ nanocomposites with an average diameter size of $12 \mathrm{~nm}$. These magnetic silica nanocomposites with a functional surface had excellent superparamagnetic properties. Accordingly, the amino-functionalized $\mathrm{Fe}_{3} \mathrm{O}_{4} / \mathrm{SiO}_{2}$ nanocomposites were used as magnetic separation carriers for immobilization of catalase (CAT). The immobilized CAT obtained through covalent attachment exhibited higher resistance of $\mathrm{pH}$ and thermal stability than the free CAT. The immobilized CAT still retained a high activity after 10 repeated batches reaction.

\section{Introduction}

As we know, enzyme has useful applications for its high catalytic performance. However, there are many limitations for the free enzymes because they have a poor stability and cannot be used repeatedly ${ }^{[1]}$. These drawbacks can be partially eliminated by immobilizing enzyme onto solid carriers ${ }^{[2,3]}$. Among various classes of materials, magnetic carriers have aroused much interest because they can be separated by external magnetic field easily ${ }^{[4,5]}$. And magnetite silica has considered as an excellent candidate because it has a multifunctional properties core with small size, superparamagnetism and low toxicity ${ }^{[6,7]}$. The silica shell is biocompatible and can be easily functionalized for bioconjugation purposes. Several methods have been developed for the preparation of silica-coated magnetic nanoparticles with core/shell structures by coating the silica shell on the preformed nanoparticles ${ }^{[8]}$.

Magnetite/silica $\left(\mathrm{Fe}_{3} \mathrm{O}_{4} / \mathrm{SiO}_{2}\right)$ nanoparticles with amino-functionalized were synthesized in a simple one-pot process. The synthetic reaction took place in a water-in-oil microemulsion system. The micoemulsion was used as a micoreactor for the formation of iron oxide, silica coated and amino-modified.

\section{Experimental}

\subsection{Materials}

Cyclohexane, Alkylphenols polyoxyethylene (OP-10), n-butanol, ferric chloride $\left(\mathrm{FeCl}_{3} \cdot 6 \mathrm{H}_{2} \mathrm{O}\right)$, ferrous chloride $\left(\mathrm{FeCl}_{2} \cdot 4 \mathrm{H}_{2} \mathrm{O}\right)$, ammonia $\left(\mathrm{NH}_{4} \cdot \mathrm{H}_{2} \mathrm{O}, 25 \%\right)$, disodium hydrogen phosphate, potassium dihydrogen phosphate, and glutaraldehyde were analytical-reagent grade or better and used without any further purification. Tetraethyl orthosilicate (TEOS, 95\%) and 3-aminopropyl-trimethoxysilane (APTES, 98\%) were purchased from Aladdin, Shanghai, China. Catalase (hydrogen peroxide oxidoreductase; EC.1.11.1.6) were purchased from Aldrich, Shanghai, China.

\subsection{Characterization}

Amino-functionalized magnetite/Silica $\left(\mathrm{NH}_{2}-\mathrm{Fe}_{3} \mathrm{O}_{4} / \mathrm{SiO}_{2}\right)$ nanoparticles were characterized with a powder X-ray diffractometer (XRD) (Bruker, D8 Focus) using a $\mathrm{Cu} \mathrm{K \alpha}$ radiation $(\lambda=1.5406 \AA)$, Fourier transform infrared analysis (FT-IR) (Thermo Nicolet, Nexus), and transmission electron 
microscope (TEM) (FEI, Tecnai G2 F20) with an accelerating voltage of $200 \mathrm{KV}$. Before TEM observation, ultrasonic dispersion was performed for 15 min for each product. Scanning electron microscopy (SEM) images of the products were taken using a field emission (FEI, Nanosem 430). Magnetic characterization was conducted on a vibrating sample magnetometer (VSM),(LDJ, 9600-1) at $300 \mathrm{~K}$.

2.3 Synthesis of amino-functionalized magnetite/silica

Firstly, Cyclohexane, OP-10 and n-butanol were mixed in a flask at the volume ratio of 20:9:6. Then a water-in-oil microemulsion containing iron salts was formed by adding ferrous $\left(\mathrm{Fe}^{2+}\right)$ and ferric $\left(\mathrm{Fe}^{3+}\right)$ solution with the molar ratio of $1: 2$ into the mixture, while stirring until the mixed emulsion became transparent. The water-in-oil microemulsion containing the basic precipitant of ammonia was prepared with the similar procedure. Then precipitant microemulsion was added into the iron salts microemulsion under vigorous agitation to produce a black microemulsion. During the experiment process, the nitrogen gas was kept passing through the solution to prevent the oxidation of $\mathrm{Fe}^{2+}$ in the system.

After aged for $2 \mathrm{~h}$, formation of the $\mathrm{Fe}_{3} \mathrm{O}_{4} / \mathrm{SiO}_{2}$ nanocomposites was carried out by adding $3 \mathrm{~mL}$ of TEOS drop by drop into the as-synthesized magnetite microemulsion directly. The TEOS molecules hydrolyzed at the interface with the reverse micelles because of the presence of the water molecules and in situ formed an amorphous silica shell on the surface of the magnetite nanoparticles. After that the mixture was kept vigorously stirring at room temperature for $3 \mathrm{~h}$. Functionalization of $\mathrm{Fe}_{3} \mathrm{O}_{4} / \mathrm{SiO}_{2}$ nanocomposites was also took place in the above microemulsion system. The amino groups were grafted by hydrolysis of $0.2 \mathrm{~mL}$ of APTES directly.

2.4 Immobilization of catalase on Magnetic Nanoparticles

As biological application of these magnetic silica nanoparticles, catalase was crosslinked on them. Glutaraldehyde was used as the crosslinking agent. The activities of CAT were measured by the hydrolysis of hydrogen peroxide in phosphate aqueous buffer at the $\mathrm{pH}$ value of 7.0. The formation of the products was evaluated by measuring the decrease in absorbance at $240 \mathrm{~nm}$ with an ultraviolet-Visible (UV-Vis) spectrophotometer (Varian, Palo Alto, CA), and the enzyme activity was calculated from the time-dependent decrease of hydrogen peroxide.

\section{Results and Discussion}

3.1 TEM and EDX analyses of the $\mathrm{NH}_{2}-\mathrm{Fe}_{3} \mathrm{O}_{4} / \mathrm{SiO}_{2}$

TEM image (Fig.1a) showed that the prepared nanocomposites had a core/shell structure, and the core with a diameter of $8 \mathrm{~nm}$ is surrounded by a $4 \mathrm{~nm}$-thick silica shell. The EDX (Fig. 1b) proved the existence of silicon in the nanocomposites.
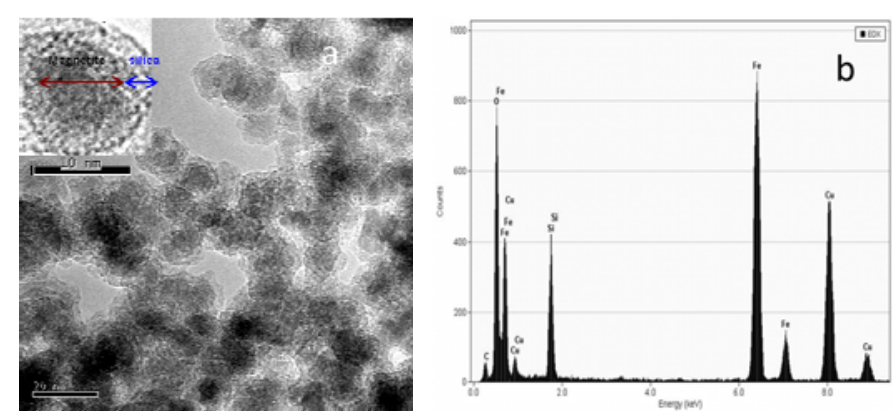

Fig.1 TEM (a) and EDX (b) of $\mathrm{NH}_{2}-\mathrm{Fe}_{3} \mathrm{O}_{4} / \mathrm{SiO}_{2}$

\subsection{XRD and FTIR analyses of the $\mathrm{NH}_{2}-\mathrm{Fe}_{3} \mathrm{O} 4 / \mathrm{SiO}_{2}$}

Then the characteristic peaks in XRD pattern (Fig.2a) $2 \theta=30.2^{\circ}, 35.6^{\circ}, 43.1^{\circ}, 53.6^{\circ}, 57.2^{\circ}$, $62.7^{\circ}$ could clearly identify the crystal cores were magnetite nanoparticles (JCPDS card No.19-0629). FTIR spectrum (Fig.2b) confirmed the existence of $-\mathrm{NH}_{2}$ bending $\left(1602 \mathrm{~cm}^{-1}\right)^{[9]}$ on the surface of the particles and the silica layer from the characteristic of Si-O-Si linkage vibration $\left(1090 \mathrm{~cm}^{-1}\right)^{[10]}$. 

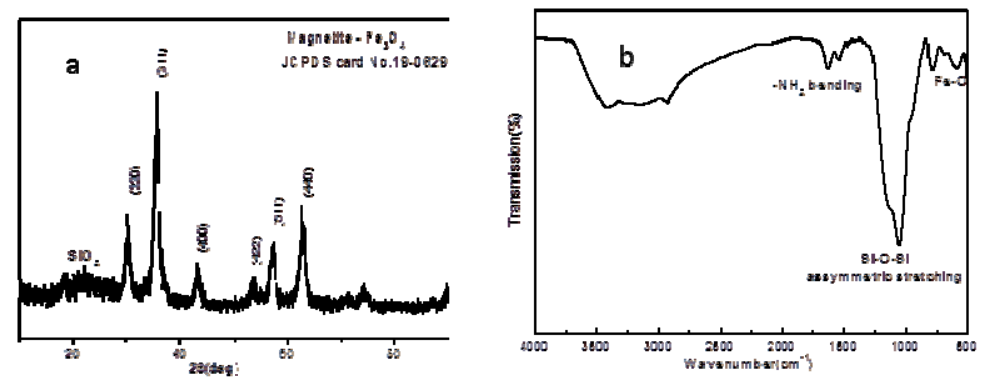

Fig. 2 XRD (a) and FTIR (b) of $\mathrm{NH}_{2}-\mathrm{Fe}_{3} \mathrm{O} 4 / \mathrm{SiO}_{2}$

\subsection{VSM analysis of the $\mathrm{NH}_{2}-\mathrm{Fe}_{3} \mathrm{O}_{4} / \mathrm{SiO}_{2}$}

Magnetic propertie of $\mathrm{NH}_{2}-\mathrm{Fe}_{3} \mathrm{O}_{4} / \mathrm{SiO}_{2}$ nanocomposites was examined on a VSM (Fig.3). The saturationmagnetization (Ms) is $27.95 \mathrm{emu} / \mathrm{g}$. It could be regarded as superparamagnetic materials since no remanence or coactivity is observed in the magnetic hysteresis curves.

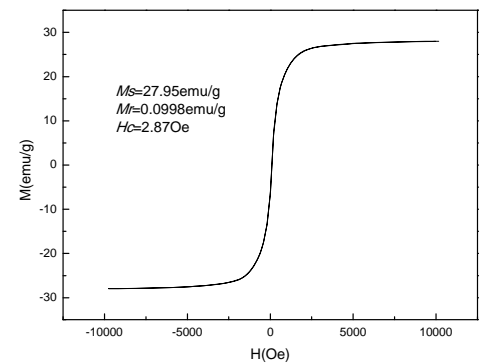

Fig.3 VSM of $\mathrm{NH}_{2}-\mathrm{Fe}_{3} \mathrm{O}_{4} / \mathrm{SiO}_{2}$

3.4 Effect of $\mathrm{pH}$ and temperature on the activity of immobilized catalase

The effect of $\mathrm{pH}$ on the activity of the free CAT and the immobilized CAT was assayed in the $\mathrm{pH}$ range of 5-9 at $40{ }^{\circ} \mathrm{C}$ (Fig.4a). In general, the immobilized CAT had a higher relative activity than the free enzyme in both acidic and alkaline conditions, these changes most depend on surface charges and structure of the carrier. To determine the effect of temperature on the apparent initial activity, the activity of the free and immobilized CAT were determined by measuring the apparent initial activity in buffer solutions at different temperature. The $\mathrm{pH}$ value of the buffer solutions were all of 7 . Here the activity was expressed in relative units [\%], where the maximal activity value at a certain temperature is set at $100 \%$. The results are shown in Fig. $4 \mathrm{~b}$. The maximal activity temperature of the immobilized CAT was at 50\% and the free CAT was at $40 \%$. The advantage of immobilized CAT could be seen clearly with the increase of temperature.
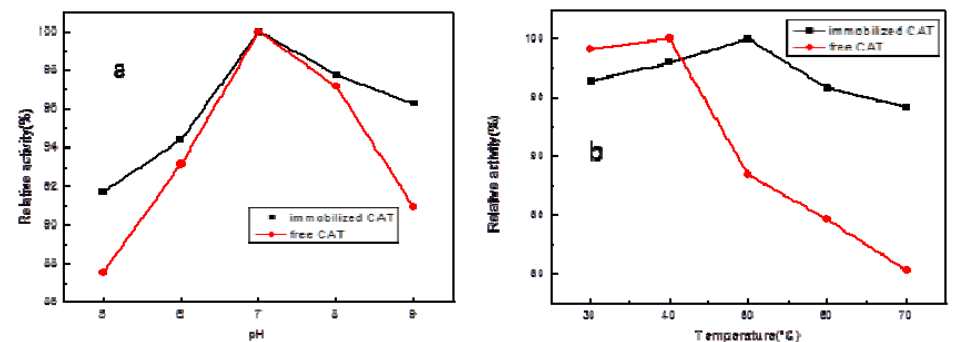

Fig.4 Effect of pH (a) and temperature (b) on the activity of immobilized CAT

\subsection{Reusability of immobilized catalase}

The reusability was also measured. After each activity measurement, the sample was washed at least six times by aqueous buffer to remove all the substrate and products from the sample before its use in the next run. The immobilized CAT can retain above $73 \%$ of activity after 10 consecutive operations (Fig.5). 


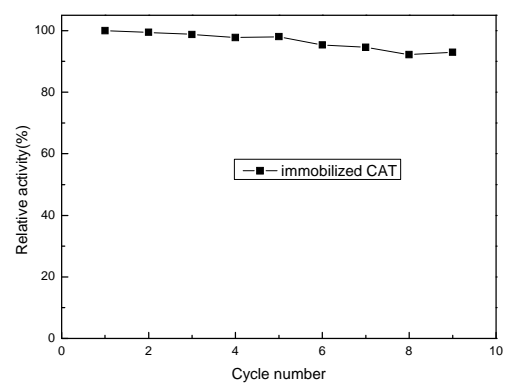

Fig.5 Reusability of immobilized CAT

\section{Conclusion}

This simple one pot method for amino-functionalized silica-coated magnetic nanoparticles synthesis can be used in enzyme technology and other bioapplications. In particular, the magnetic separation using a magnet field will make the recycling of enzymes much easier, and the automation of biocatalysis can be realized with an economical advantage.

\section{Acknowledgements}

This work was financially supported by the Natural Science Foundation of Hebei Provinc (D2014202074), Science and Technology Research and Development Program of Hebei Province (12276711D).

\section{References}

[1] F.Y. Cheng, C.H. Su, Y.S. Yang, C.S. Yeh, C.Y. Tsai, C.L. Wu, M.T. Wu, D.B. Shi, Biomaterials 26 (2005), p.729-738.

[2] C. Hou, Y. Wang, H. Zhu, H. Wei. Chem. Eng. Sci. 283 (2016), p.397-403

[3] A.K. Gupta, M. Gupta, Biomaterials. 26 (2005), p. 3995-4021.

[4] X.Q. Liu, Z.Y. Ma, J.M. Xing, H.Z. Liu.J. Magn. Magn. Mater. 270 (2004) p.1-6

[5] B.F. Shi, Y.Q. Wang, J.W. Ren, X.H. Liu, Y. Zhang, Y.L. Guo, Y. Guo, G.Z. Lu. J. Mol. Catal. B-Enzym. 63 (2010), p. 50-56.

[6] J.Huang, R. Zhao, H.Wang, W.Q Zhao, L.Y. Ding, Biotechnol. Lett. 32 (2010),p.817-821.

[7] Z. Z. Xu, C. C. Wang, W. L. Yang, S. K. Fu. J. Mater. Sci. 40(2005), p.4667-4669.

[8] S. H. Araghi, M. H. Entezari. Appl. Surf.Sci. 333(2015), p. 68-77.

[9] J.Hong, P.J. Gong, J.H. Yu, D.M. Xu, H.W. Sun, S. Yao. J. Mol. Catal. B-Enzym. 42 (2006),p. 99-105.

[10] S.H. Araghi, M.H. Entezari, M. Chamsaz. Micropor. Mesopor.Mat.218(2015), p.101-111. 